\title{
DEVELOPMENT AND IN-VITRO EVALUATION OF TEMPERATURE SENSITIVE AND PH SENSITIVE IN-SITU OCCULAR GEL OF DICLOFENAC SODIUM
}

\section{PEEYUSH KAUSHIK ${ }^{*}$,SHAVETA SHARMA ${ }^{1}$, ASHISH S. MISHRA ${ }^{2}$, DEEPALI TOMAR ${ }^{3}$ \& LALAN KUMAR SAH ${ }^{4}$}

${ }^{* 1}$ Chandigarh College of Pharmacy, Landran, Mohali, Punjab, India

${ }^{2}$ Faculty of Pharmacy, Upums, Saifai, Etawah, Uttar Pradesh, India

${ }^{3}$ Lala Birkha Ram College of Pharmacy, Golpura, Punchkula, Haryana, India

${ }^{4}$ Punjabi University, Patiala, Punjab, India

\begin{abstract}
In-situocular gels are the systems, which are generally used in the form of solutions or suspensions. They are equipped for undergoing quick phase transformation from sol to gel activated by external factors (like temperature, pH etc.) on instillation in cul-de-sac of eye. The goal of the current investigation was "the formulation and evaluation of thermos and $\mathrm{pH}$ responsive in-situ gel for ophthalmic delivery". Diclofenac sodium is famously consumed as NSAIDs for the treatment of postoperative aggravation in patients who have experienced cataract extraction, in transitory assistance of pain and photophobia undergoing corneal refractive medical procedure. Nonetheless, poor retention of drug concentration, prompt dilution on instillation, and wash out, diminishes the drug's remedial advantages, when utilized in sort of ordinary eye drops. Ophthalmic gel with a muco-adhesive polymer (Poloxamer 407)was picked as it experiences instantaneous gel formation because of its thermo responsive nature. The carbopol 934 was additionally consolidated as a thickener and $\mathrm{pH}$ responsive so as to accomplish the perfect consistency for improved and controlled drug release. The developed formulation were evaluated for clarity, $\mathrm{pH}$ estimation, spreadability, FTIR study, gelling limit, drug content, thickness study, and in vitro drug release study in comparison with ordinarydosage form. Along these lines, in situ gel based system comprising thermo and $\mathrm{pH}$ responsive triggered system are often a crucial methodology for ophthalmic drug delivery in comparison to standard systems.

KEYWORDS: Ophthalmic; Inflammation; Conventional, Photophobia
\end{abstract}

Received: Nov 26, 2020; Accepted: Dec 16, 2020; Published: Dec 30, 2020; Paper Id.: IJMPSDEC20203

\section{INTRODUCTION}

The most intense issueencounteredin ophthalmic drug delivery system is the maintenance and accomplishment of minimum drug concentration required at the target site inside the eye. Various dosage forms for ophthalmic use were accessible in market, such as ointments, ocular inserts, solutions; in situ gels that have been explored in an attempt to increase the bioavailability to extend the Increased pre-corneal residence time and decreased nasolacrimal drainage of medicine for topical use to the eye. The corneal contact time of drug has been expanded to variabledegrees of instrument by these dosage forms. However, they have not been collectively acknowledged, because of blurred vision (e.g. ointments) or lack of patient compliance (e.g. inserts).

A large portion of the dosage form was used in suspensions or solutions form. Rapid pre-corneal elimination observed with traditional ocular dosages form ends in poor drug bio-availability. The eye drops having very poor 
bioavailability due to their fast drainage of during lachrymation in tear fluid in eyes. Ease of direction in case of dosages fairly viscous solution and improved patient acceptability. Obscured vision and hydrogel dosage form including lachrymation.

In this way, these problems may be overwhelmed with the aid of fabricating the drug as a formulation that experiences in-situ gel formation upon immediate ophthalmic administration. The mechanism of in situ gel based on experiences gelation after instillation in the cu-de-ac conditioning of the eye due to physico-synthetic changes occurring in the eye. It is based on the thermal and $\mathrm{pH}$ sensitive. It expands bioavailability of medication due to the pre-corneal residence time and decreases the percentage drug loss from tear formulating in situ gel.

The current work is done based on the "formulation and evaluation of in situ gel forming ophthalmic formulation containing diclofenac sodium". In which in situ gel phase transition sol-gel happens on the corneal surface. Atthe time of instillation dosage form structure is in the eye in solution phase and soon later after interacting with corneal layer and calcium ion with surrounding $\mathrm{pH}$ of 7.4 it transforms into transparent gel depo. In this manner, this sort of formulations has advantage of both the solutions and gels as they may improve the bioavailability by retention time of the formulation as well the drug, accuracy and ease of administration ${ }^{1-3}$.

\subsection{Drug Profile}

\subsubsection{Diclofenac Sodium}

Diclofenac is a non-steroidal anti-inflammatory drug (NSAID) taken orally or applied as an analgesic to reduce pain and inflammation in certain conditions. It is supplied as or contained in medications under a variety of trade names.

\subsubsection{Structure}

[Figure 1: about here]

\subsubsection{Chemical Profile}

- IUPAC Name:- [(2, 6-Dichlorophenyl) amino] benzene acetic acid sodium salt ${ }^{5}$

- Molecular Formula:- $\mathrm{C}_{14} \mathrm{H}_{10} \mathrm{Cl}_{2} \mathrm{NO}_{2} \cdot \mathrm{Na}$

- Molecular Weight:-318.13

- Appearance: Slightly hygroscopic, crystalline powder, white to slightly yellowish.

- Category: Non-steroidal anti-inflammatory drug (NSAID)

- Melting Point: $283^{\circ}-285^{\circ} \mathrm{C}$ (Salt) $156^{\circ}-158^{\circ} \mathrm{C}$ (Free Acid)

- Solubility:Freely soluble in water, PBS (Phosphate buffer saline) pH 7.2, ethanol, methanol, and acetone.

- Half Life : 1-2 hr. (35\% of the drug enters enterohepatic recirculation)

- Bioavailability: $79 \%$

- Uses:In pain, inflammation and dysmenorrhea.

\subsubsection{Mechanism of Action}

The crucial mechanism behind its anti-inflammatory, anti-pyretic, and pain-relieving action is inhibition of synthesis of prostaglandins via cyclooxygenase (COX-2) inhibition. It also exhibits bacteriostatic activity by inhibiting bacterial DNA synthesis. 


\subsubsection{Adverse effect:}

- Abdominal cramps or pain

- Hypersensitivity

- Constipation And Diarrhoea

- Dizziness, Nausea and Vomiting

- Hepatic toxicity

- Hematologic toxicity

- Renal Toxicity

- Hypertension

- Congestive Heart Failure

- Anaphylactic Reactions

In situ ocular gel system based on gelling systemscomprise of polymer that can show phase transitions sol-to-gel stage in the cul-de-sacthat leads to better patient compliance, persistent and prevent the loss of the medication through tear drainage because of change in definite physico-chemical factors like temperature, ionic changes, and $\mathrm{pH}$ changes in the environment. The phase transition sol-to-gel phase on the eye surface contingent upon the various strategies utilized which comprise of sensitivity towards temperature ${ }^{6}$, ion activation, $\mathrm{pH}$, ultrasonic, chemical material, electric and attractive field. The present work is based on some of the most commonly used techniques, that are as per the following:

- Temperature dependent system (e.g. Pluronics and tetronics)

- PH-triggered system (e.g. cellulose acetate hydrogen phthalate latex)

- Temperature subordinate framework (e.g. pluronics and tetronics),

- Ion activated system (gelrite) ${ }^{7}$.

In situ visual gel based drug delivery system is composed of active pharmaceutical ingredients, co-polymer, polymers, and excipients. Poloxamer 407, an ophthalmic gel framing mucoadhesive polymer was picked because the polymer and thickness enhancer carbopol 934 is employed as copolymer.

Poloxamer are non-ionic poly (ethylene oxide) (PEO) - poly (propylene oxide) (PPO) copolymers. They are utilized in medicinal plans as dispersing agents, surfactants, gelling agents, emulsifiers, solubilizers, and in-vivo absorbance enhancer. Poloxamer are regularly regarded as "functional excipients" due to the fact that they are basic components and assume a significant job within the formulation. Poloxamer have comparative synthetic structures yet with different molecular weightand arrangement of the hydrophilic PEO block (a) and hydrophobic PPO block(b).

Carbopol Carbomers are synthetic polymers of acrylic acid with high atomic weight and are crosslinked with either allyl ethers of pentaerythritol orballylsucrose. They contain $56-68 \%$ of carboxylic acid (- $\mathrm{COOH})$ groups as determined on the dry basis. The PhEur has a solitary monograph describing carbomer in comparison with the USP that contains a few monographs illustrating individual carbomer grades that vary in aqueous viscosity and in labelling for oral or non-oral use ${ }^{8-12}$.

\section{MATERIAL AND METHOD}

Diclofenac sodium was obtained from Arti drugs Ltd. Faridabad, Poloxomer 407 and carbopol obtained from. All other chemicals and reagents were of procured from $\mathrm{CDH}$ Chemicals and are of analytical grade. 


\subsection{ANALYTICAL METHOD DEVELOPMENT}

2.1.1. Determination of $\lambda_{\max }$ of Diclofenac sodium: Different dilutions of diclofenac sodium were prepared in Water (as described above) and from the above solution one sample $(8 \mu \mathrm{g} / \mathrm{ml})$ was taken and scanning was done in range of 200-400 $\mathrm{nm}$ using UV-Visible double beam Spectrophotometer. The UV peak was observed at $276 \mathrm{~nm}$.

\subsubsection{Preparation of standard curve of diclofenac sodium in different solvents}

Standard curve of the drug diclofenac sodium was prepared in different solvents (water \& phosphate buffer 6.8) and value of $\mathrm{R}^{2}$ and slope were determined.

- Preparation of standard curve of diclofenac sodium in water

- Different dilutions of diclofenac sodium were prepared in water and water to give a conc. $3 / 30 \mathrm{ug} / \mathrm{ml}$. The absorbance of these solutions was determined against the water as blank at 276nm using UV-Visible double beam spectrometer.

- $\quad$ Standard curve of diclofenac sodium in phosphate buffer $\mathrm{pH} 6.8$

- Different dilutions of diclofenac sodium were prepared in Phosphate Buffer pH 6.8 as described in chapter 6 to give solutions with concentration in the range final concentration $3-30 \mu \mathrm{g} / \mathrm{ml}$. The absorbance of these solutions was measured against the phosphate Buffer ( $\mathrm{pH}$ 6.8) as blank at $276 \mathrm{~nm}$ using UV-Visible double beam spectrophotometer.

\subsection{Formulation Development and Evaluation}

In-situ gels were formulated by cold method. In this method, $10 \mathrm{mg}$ of drug was dissolve in $5 \mathrm{ml}$ of chilled distilled water $\left(4^{\circ} \mathrm{C}\right)$. To this various concentration of Poloxamer- 407 were dissolved at cold conditions $\left(4^{\circ} \mathrm{C}\right)$, formed solution a. And carbopol dissolved in $5 \mathrm{ml}$ of water and soaked in water for 24 hours. Then solution A is mixed in solution B in continuousstirring maintaining the temperature $4^{\circ} \mathrm{C}$ in water bath on magnetic stirrer. The numbers of formulation were made shown in table. Later drug was incorporated and stirred until clear solution was obtained. Finally it was kept overnight in $\left(4-10^{\circ} \mathrm{C}\right)$ freezing conditions. ${ }^{[10]}$

\subsection{CHARACTERIZATION AND EVALUATION OF OCULAR GEL}

\subsubsection{Clarity Test and Appearance of Formulations}

All formulation was visually tested for gel preparation at different concentration of drug and polymer.

\subsection{2 pH Estimation:}

The $\mathrm{pH}$ of human eye and tears is found to be in the range of 7-7.4. But it can tolerate about 7-7.5. Prepared ophthalmic formulations should be within the range the tears'pHthat can tolerate in order to reduce eye irritation. $\mathrm{pH}$ of all formulations was tabulated in Table.

\subsubsection{Drug Content}

Each formulation $5 \mathrm{ml}$ of was taken in a centrifuge and centrifuge in a cooling centrifuge at $15000 \mathrm{rpm}$ for 30 min. Filter the solution with the aid of $0.45 \mu$ pore size (Whatmann) filter paper. The content of the drug was estimated using UVSpectrophotometer (Shimadzu UV - 1800, Japan) at 276nm. 


\subsubsection{Partition Coefficient}

It was determined as the ratio of concentration of drug in octanol to the concentration of drug in water. The Partition coefficient values were calculated as $\log \mathrm{P}$.

Concentration of drug (non-aqueous phase)

$$
\mathrm{K}_{\mathrm{o} / \mathrm{w}}=
$$

Concentration of drug (aqueous phase)

[Table 1; about here]

\subsubsection{FTIR Spectra ${ }^{[13]}$}

The obtained FT-IR spectra's observedat wavelength $4000 \mathrm{~cm}^{-1}-400 \mathrm{~cm}^{-1}$ are shown in fig 6-8and characteristic peaks are shown in table 7-9

\subsubsection{Measurement of Viscosity}

Viscosity measurement of the formulations was at $37^{\circ} \mathrm{C}$ temperatures. Viscosity was checked by spindle no. 64 at different rpm of final formulation.

\subsubsection{Spreadability of gel}

The spreadability of ocular gel of final formulation f15 was observed $24.4 \pm 05 \mathrm{~g} . \mathrm{cm} / \mathrm{sec}$.

\subsubsection{In-vitro Drug release study}

The in-vitro drug release of Formulation F15 and Pure drug was given in a table 12

\section{RESULTS}

\subsection{Determination of $\lambda_{\max }$ of Diclofenac Sodium}

The UV peak was observed at $276 \mathrm{~nm}$.

[Figure 2: about here]

\subsection{Preparation of standard curve of diclofenac sodium in different solvents}

\section{Standard curve of diclofenac sodium in water}

[Table 2: about here]

[Figure 3: about here]

\section{Standard curve of diclofenac sodium in phosphate buffer $\mathrm{pH} 6.8$}

[Table 3: about here]

[Figure 4: about here]

3.3. The different trails performed and the number of formulation prepared to optimizes the final formulation. [Table 4; about here] 


\subsection{CHARACTERIZATION AND EVALUATION OF OCULAR GEL}

\subsubsection{Clarity Test and Appearance of Formulations}

Clear gel was observed in the final formulation $\mathrm{f} 15$.

\subsection{2. pH Estimation:}

The $\mathrm{pH}$ of all gel formulation was found to be in a range of 7-7.4 that is between physiological ranges of $\mathrm{pH}$ of eye tear. ${ }^{[12]}$ [Table 5; about here]

\subsubsection{Drug Content}

The percentage of drug content was varied in between $73.12 \pm 0.46$ to $97.12 \pm 0.11$.

[Table 6; about here]

[Figure 5: about here]

\subsubsection{Partition coefficient}

The partition coefficient of Diclofenac sodium in n- Octanol: Water was found to be 0.874 which specifies that the drug is of Hydrophilic nature.

\subsubsection{FTIR Spectra}

The obtained FT-IR spectra's were shown below:

\section{- $\quad$ FTIR Spectra of drug (diclofenac sodium)}

[Figure 6; about here]

[Table 7; about here]

- $\quad$ FTIR spectra of physical mixture

[Figure 7; about here]

[Table 8; about here]

\section{- $\quad$ FTIR Spectra of final formulation}

[Figure 8; about here]

[Table 9; about here]

\subsubsection{Gelation and Gel Melting Point Temperature:}

All the formulations tested for this study. Individual studied effect of excipients on gelation (T1) and gel m.p temperature (T2). The resulted values were shown in Table 11. Formulations F13 to F18 found to be as the concentration of Carbopol increased, the T1 decreased. Whereas the T2 was found to be increased. This might be due to greater number and volume occupied by the micelles at low temperature. Therefore gel range, broadens with the concentration of polymer. In all formulation it is observed that the Ploxomer-407 was used as gelling or viscosity enhancing agent. On its concentration an increased to $\mathrm{T} 1$ decreased and $\mathrm{T} 2$ an increased. 
[Figure 9; about here]

[Table 10; about here]

\subsubsection{Measurement of Viscosity}

Viscosity measurement of the formulations was at $37{ }^{\circ} \mathrm{C}$ temperatures. Viscosities were checked by spindle no. 64 at different rpm of final formulation.

[Figure 10; about here]

[Table 11; about here]

\subsubsection{Spreadability of Gel}

The spreadability of ocular gel of final formulation $\mathrm{f} 15$ was observed $24.4 \pm 05 \mathrm{~g} . \mathrm{cm} / \mathrm{sec}$.

\subsubsection{In-vitro Drug Release Study}

The in-vitro drug release profile of Formulation F15 and Pure drug was given in a table 15

[Table 12; about here]

[Figure 11; about here]

\subsubsection{In-vitro Drug Release Kinetic}

Given below is the data of in-vitro drug release kinetic study of formulation F12.

\section{- Zero order}

[Figure 12; about here]

\section{- $\quad$ First Order}

[Figure 13; about here]

\section{- Higuchi}

[Figure 14; about here]

\section{SUMMARY AND CONCLUSIONS}

The present study, ocular in-situ gel of diclofenac sodium was effectively developed and assessed for its in vitro performance. The in situ gel of these formulations is responsible for facilitating enhancement of drug, bioavailability due to improved pre-corneal residence time and decreased lacrimal drug drainage.

The various performualtion study of drug was performed. The drug's melting point was determined by capillary fusion method and was found to be $283 \pm 0.76$. Solubility of drug was more soluble in distilled water than $0.1 \mathrm{~N} \mathrm{HCl}$ and phosphate buffer $(\mathrm{pH} 6.8$ and 7.2). One sample $(8 \mu \mathrm{g} / \mathrm{ml})$ was taken and scanning was done in the range of 200-400 $\mathrm{nm}$ using UV-Visible Spectrophotometer. The UV peak was observed at $276 \mathrm{~nm}$ and standard curve equation was observed $\mathrm{y}=$ $0.031 \mathrm{x}+0.047, \mathrm{R}^{2}=0.998$. FTIR spectra was shows the presence of functional group and confirm the presence of the drug in the formulation ${ }^{13,14}$. 
The in-situ gel was formed by the cold method that was based on thermo sensitive and $\mathrm{pH}$ sensitive system. Various trails were performed with poloxamer and carbopol to optimize the polymer concentration and final concentration optimizes were $17 \%$ and $0.3 \%$ respectively. The concentration were optimizes on the bases of their clarity, pH, gelling temperature, drug content, spreadability, viscosity and drug release. The final formulation evaluation results were $\mathrm{pH}$ of final formulation was observed 7.38 and gelling temperature was observed $36.52 \pm 0.55^{\circ} \mathrm{C}$. Drug content $93.07 \%$ was observed. The viscosity of final gel prepared was studied by using Brookfield Viscometer Spindle S64 and viscosity at 10rpm, 60rpm, and $100 \mathrm{rpm}$ were found to be $14800,4740,3370^{15}$.

The in-vitro release profile of the formulated in-situ gel was carried out via Franz diffusion cell. The drug release was observed $75 \%$ after 8 hours. Where, as marketed formulation eye drop of diclofenac sodium release $91 \%$ in 4 hours. The following result observed were conclude that in-situ gel provide sustained drug release in ocular drug delivery system and better bioavailability due to its increased pre-corneal residence time and decreased lacrimal drainage of the drug ${ }^{16,17}$.

Almost certainly, the quantity of distributions, licenses and advances on the In situ gel are enlarging, however at a significant consistent pace. Impressive wariness and lack of care will in general fuel the hesitance to attempt examination into this moderately novel and more valuable in situ gel approach, which could somehow or another bring a great deal of break. Subsequently, it is the most advantageous chance to increase the exploration endeavours on these promising drug delivery system coordinated at overcoming the bioavailability improving production on large scale.

The current proposition is a genuine endeavour to give a holistic record on practically all the crucial terrains of the in situ gel formulations. This ought to give the ideal catalyst to the product development researcher, encouraging further evolution of in situ gel research and cutting edge product launches. Inevitably, the day isn't far when the advantages of in situ gel plans would be gathered by medicate industry and exploration gatherings to their fullest addition.

\section{REFERENCES}

1. Makwana SB, Patel VA, Parmar SJ. Development and characterization of in-situ gel for ophthalmic formulation containing ciprofloxacin hydrochloride. Results in pharma sciences. 2016 Jan 1; 6:1-6.

2. Singh B, Bandopadhyay S, Kapil R, Singh R, Katare OP. Self-emulsifying drug delivery systems (SEDDS): formulation development, characterization, and applications. Critical Reviews ${ }^{\mathrm{TM}}$ in Therapeutic Drug Carrier Systems. 2009; 26(5).

3. Attama AA, Umeyor CE. The use of solid lipid nanoparticles for sustained drug release. Therapeutic delivery. 2015 Jul; 6(6):669-84.

4. Pardhan S, Mughal N, Mahomed I. Self-reported eye disease in elderly South Asian subjects from an inner city cluster in Bradford: a small-scale study to investigate knowledge and awareness of ocular disease. Eye. 2000 Jul; 14(4):620-4.

5. Dhyani A, Kumar G. A NEW VISION TO EYE: NOVEL OCULAR DRUG DELIVERY SYSTEM. Pharmacophores. 2019 Apr 1; $10(1): 13-20$.

6. Rawas-Qalaji M, Williams CA. Advances in ocular drug delivery. Current eye research. 2012 May 1; 37(5):345-56.

7. Ramesh Y, Reddigari JR, Kothapalli CB. Formulation and evaluation of tropicamide in-situ gels loaded solid lipid nanoparticles for ocular drug delivery. Journal of Drug Delivery and Therapeutics. 2018 Jun 18; 8(2):194-207.

8. Sharma RK, Kalra N, Dwivedi J, Jeyabalan G, Singh G. Development, Characterization and bioavailability enhancement of oral floating sustained release beads containing Indomethacin. Indian Journal of Pharmaceutical and Biological Research. 2018 Dec 31; 6(04):48-54. 
9. Kulinsky L, Madou MJ. BioMEMs for drug delivery applications. InMEMS for Biomedical Applications 2012 Jan 1 (pp. $218-$ 268). Woodhead Publishing.

10. Nayak AK, Hasnain MS. Advanced Biopolymeric Systems for Drug Delivery.

11. Karatas A, Boluk A, Hilal Algan A. Poloxamer/Chitosan In Situ Gelling System for Ocular Delivery of Ofloxacin. Current Drug Therapy. 2014 Dec 1; 9(4):219-25.

12. Chakraborty T, Das MK. De novo approach to utilize mango (Mangifera indica L.) seed kernel lipid in pharmaceutical lipid nanoformulation. Journal of pharmaceutical innovation. 2017 Sep 1; 12(3):226-37.

13. Üstündă̆ Okur N, Çağlar EŞ, Siafaka PI. Novel Ocular Drug Delivery Systems: An Update on Microemulsions. Journal of Ocular Pharmacology and Therapeutics. 2020 Apr 7.

14. Thakur A, Jain S, Pant A, Sharma A, Kumar R, Sharma G, Singla N, Suttee A, Kumar S, Barnwal RP, Katare OP. CYCLODEXTRIN DERIVATIVE ENHANCES THE OPHTHALMIC DELIVERY OF POORLY SOLUBLE AZITHROMYCIN. bioRxiv. 2020 Jan 1.

15. Saerens L, Dierickx L, Quinten T, Adriaensens P, Carleer R, Vervaet C, Remon JP, De Beer T. In-line NIR spectroscopy for the understanding of polymer-drug interaction during pharmaceutical hot-melt extrusion. European journal of pharmaceutics and biopharmaceutics. 2012 May 1; 81(1):230-7.

16. Tekade RK, Maheshwari R, Tekade M. INational Institute of Pharmaceutical Education and Research (NIPER)-Ahmedabad, Gandhinagar, India; 2BM College of Pharmaceutical Education and Research, Indore, India; 3Technocrats Institute of Technology Campus, Bhopal, India. Biopolymer-Based Composites: Drug Delivery and Biomedical Applications. 2017 Jun $15: 81$.

17. Maniruzzaman M, Nokhodchi A. Advanced implantable drug delivery systems via continuous manufacturing. Critical Reviews ${ }^{\mathrm{TM}}$ in Therapeutic Drug Carrier Systems. 2016; 33(6).

18. PATIL, TAZEEN, et al. "Fungi: an ideal biotransformation model for mimicking mammalian drug metabolism." Int. J. Med. Pharm. Sci. 4 (2014): 15-24.

19. ABDUL-RAHMAN, ABEER MUDHAFAR, and ASHWAQ JABBAR AL-MIAHY. "EVALUATION OF THE EFFECT OF DICLOFENAC SODIUM ON INH-INDUCED SEIZURES. " injury 6: 9. International Journal of Medicine and Pharmaceutical Science (IJMPS) 7.3, Jun 2017, 63-68

20. MEMON, NAZIMA, and RASHMI DESHPANDE. "EVALUATION OF BUPRENORPHINE AS AN ADJUNCT TO LIGNOCAINE AND BUPIVACAINE MIXTURE IN AXILLARY PERIVASCULAR BLOCK." International Journal of General Medicine and Pharmacy (IJGMP)3.3, May 2014, 41-46

21. VASUDHA, D., et al. "POLYMERS AND PLASTICIZERS USED IN TRANSDERMAL DRUG DELIVERY: AN OVERVIEW." IASET: International Journal of Applied Chemistry and Pharmaceutical Sciences (IASET: IJACPS) 1.1, Feb - Mar 2016; 1-14 


\section{TABLES}

Table 1: Determination of partition coefficient

\begin{tabular}{|l|l|l|}
\hline \multicolumn{1}{|c|}{ Partition coefficient of drug } & \multicolumn{1}{|c|}{ Solvent system } & Log p Values \\
\hline Diclofenac sodium & n-octanol:water & $0.884 \pm 0.03$ \\
\hline
\end{tabular}

Table 2: Concentration of different dilution and their absorbance value

\begin{tabular}{|c|c|c|}
\hline Sr. No. & Concentration $\boldsymbol{\mu g} / \mathbf{m l}$ & Absorbance \\
\hline 1 & 3 & $0.134 \pm 0.003$ \\
\hline 2 & 6 & $0.231 \pm 0.002$ \\
\hline 3 & 9 & $0.337 \pm 0.005$ \\
\hline 4 & 12 & $0.427 \pm 0.001$ \\
\hline 5 & 15 & $0.533 \pm 0.002$ \\
\hline 6 & 18 & $0.628 \pm 0.007$ \\
\hline 7 & 21 & $0.743 \pm 0.005$ \\
\hline 8 & 24 & $0.823 \pm 0.002$ \\
\hline 9 & 27 & $0.898 \pm 0.001$ \\
\hline 10 & 30 & $0.986 \pm 0.005$ \\
\hline
\end{tabular}

Table 3: Concentration of different dilution and their absorbance value

\begin{tabular}{|c|c|c|}
\hline Sr. No. & Concentration $(\boldsymbol{\mu g} / \mathbf{m l})$ & Absorbance \\
\hline 1 & 3 & $0.072 \pm 0.005$ \\
\hline 2 & 6 & $0.153 \pm 0.002$ \\
\hline 3 & 9 & $0.241 \pm 0.003$ \\
\hline 4 & 12 & $0.337 \pm 0.001$ \\
\hline 5 & 15 & $0.408 \pm 0.004$ \\
\hline 6 & 18 & $0.498 \pm 0.007$ \\
\hline 7 & 21 & $0.574 \pm 0.005$ \\
\hline 8 & 24 & $0.661 \pm 0.003$ \\
\hline 9 & 27 & $0.741 \pm 0.005$ \\
\hline 10 & 30 & $0.821 \pm 0.003$ \\
\hline
\end{tabular}

Table 4: List of number of formulation prepared.

\begin{tabular}{|l|l|l|l|l|l|}
\hline SR.NO. & $\begin{array}{c}\text { FORMULATION } \\
\text { CODE }\end{array}$ & DRUG(Mg) & $\begin{array}{c}\text { POLAXOMER } \\
188(\text { CONC. })\end{array}$ & $\begin{array}{c}\text { POLAXOMER } \\
407 \text { (CONC. })\end{array}$ & $\begin{array}{c}\text { CARBOPOL934 } \\
\text { (CONC) }\end{array}$ \\
\hline 1 & F1 & 10 & $10 \%$ & & \\
\hline 2 & F2 & 10 & $15 \%$ & & \\
\hline 3 & F3 & 10 & $16 \%$ & & \\
\hline 4 & F4 & 10 & $17 \%$ & & \\
\hline 5 & F5 & 10 & $18 \%$ & & \\
\hline 6 & F6 & 10 & $19 \%$ & & \\
\hline 7 & F7 & 10 & $20 \%$ & & \\
\hline 8 & F8 & 10 & & $15 \%$ & \\
\hline 9 & F9 & 10 & & $16 \%$ & \\
\hline 10 & F10 & 10 & & $17 \%$ & \\
\hline 11 & F11 & 10 & & $20 \%$ & \\
\hline 12 & F12 & 10 & & $17 \%$ & $.1 \%$ \\
\hline 13 & F13 & 10 & & & \\
\hline
\end{tabular}




\begin{tabular}{|l|l|l|l|l|l|}
\hline 14 & F14 & 10 & & $17 \%$ & $.2 \%$ \\
\hline 15 & F15 & 10 & & $17 \%$ & $.3 \%$ \\
\hline 16 & F16 & 10 & & $17 \%$ & $.4 \%$ \\
\hline 17 & F17 & 10 & & $17 \%$ & $.5 \%$ \\
\hline 18 & F18 & 10 & & $17 \%$ & $.6 \%$ \\
\hline
\end{tabular}

Table 5: pH and Appearance of formulation:

\begin{tabular}{|c|c|c|c|}
\hline S. No. & Formulation Code & PH & Appearance \\
\hline 1 & F1 & 5.91 & Gel not formed \\
\hline 2 & F2 & 6.31 & Gel not Formed \\
\hline 3 & F3 & 6.51 & Gel not Formed \\
\hline 4 & F4 & 6.65 & Gel not Formed \\
\hline 5 & F5 & 5.7 & Gel not Formed \\
\hline 6 & F6 & 5.8 & Gel not formed \\
\hline 7 & F7 & 5.2 & Gel not formed \\
\hline 8 & F8 & 7.6 & Less Viscous \\
\hline 9 & F9 & 7.1 & Less Viscous \\
\hline 10 & F10 & 7.4 & Less Viscous \\
\hline 11 & F11 & 7.2 & Less Viscous \\
\hline 12 & F12 & 6.95 & Less Viscous \\
\hline 13 & F13 & 7.4 & Less Viscous \\
\hline 14 & F14 & 7.45 & Less Viscous \\
\hline 15 & F15 & 7.38 & Gel formed \\
\hline 16 & F16 & 7.4 & Highly Viscous \\
\hline 17 & F17 & 7.43 & Highly Viscous \\
\hline 18 & F18 & 7.42 & Highly Viscous \\
\hline & & & \\
\hline
\end{tabular}

Table 6: Drug content in formulation

\begin{tabular}{|c|c|c|}
\hline S.No & Formulation Code & Per cent Drug Content \\
\hline 1 & F1 & $95.02 \pm 0.24$ \\
\hline 2 & F2 & $94.34 \pm 0.41$ \\
\hline 3 & F3 & $93.21 \pm 0.34$ \\
\hline 4 & F4 & $95.63 \pm 0.42$ \\
\hline 5 & F5 & $97.12 \pm 0.11$ \\
\hline 6 & F6 & $91.78 \pm 0.38$ \\
\hline 7 & F7 & $88.18 \pm 0.24$ \\
\hline 8 & F8 & $87.44 \pm 0.36$ \\
\hline 9 & F9 & $73.34 \pm 0.24$ \\
\hline 10 & F10 & $73.12 \pm 0.46$ \\
\hline 11 & F11 & $73.26 \pm 0.32$ \\
\hline 12 & F12 & $75.68 \pm 0.62$ \\
\hline 13 & F13 & $90.08 \pm 0.52$ \\
\hline 14 & F14 & $90.67 \pm 0.24$ \\
\hline 15 & F15 & $93.07 \pm 0.76$ \\
\hline 16 & F16 & $92.56 \pm 0.41$ \\
\hline 17 & F17 & $92.67 \pm 0.18$ \\
\hline 18 & F18 & $93.80 \pm 0.90$ \\
\hline
\end{tabular}

Table 7: Interpretation of Diclofenac Sodium FT-IR spectrum

\begin{tabular}{|l|l|c|}
\hline \multicolumn{1}{|c|}{ Characteristic peaks } & Reported $\left(\mathbf{c m}^{-1}\right)$ & Observed $\left(\mathbf{c m}^{-1}\right)$ \\
\hline $\mathrm{C}-\mathrm{Cl}$ alkyl halides & $850-550$ & 839.93 \\
\hline
\end{tabular}




\begin{tabular}{|l|l|l|}
\hline $\mathrm{C}=\mathrm{O}$ (aldehydes) & $1740-1620$ & 1665.07 \\
\hline $\begin{array}{l}-\mathrm{N}-\mathrm{H}(\text { primary and secondary } \\
\text { amine) }\end{array}$ & $3400-3250$ & 3383.67 \\
\hline $\mathrm{C}=\mathrm{C}($ alkenes $)$ & $1680-1640$ & 1665.07 \\
\hline $\mathrm{C}-\mathrm{OH}($ alcohols $)$ & $3500-3200$ & 3477.05 \\
\hline
\end{tabular}

Table 8: Interpretation of physical mixture FT-IR spectrum

\begin{tabular}{|l|l|l|}
\hline $\mathrm{C}-\mathrm{Cl}$ alkyl halides & $850-550$ & 838.42 \\
\hline $\mathrm{C}=\mathrm{O}$ (aldehydes) & $1740-1620$ & 1635.04 \\
\hline $\begin{array}{l}-\mathrm{N}-\mathrm{H} \text { (primary and secondary } \\
\text { amine) }\end{array}$ & $3400-3250$ & 3383.65 \\
\hline $\mathrm{C}=\mathrm{C}($ aromatic) & $1680-1640$ & 1665.07 \\
\hline $\mathrm{C}-\mathrm{OH}($ alcohols) & $3500-3200$ & 3253.67 \\
\hline
\end{tabular}

Table 9: Interpretation of physical mixture FT-IR spectrum

\begin{tabular}{|l|l|l|}
\hline $\mathrm{C}-\mathrm{Cl}$ alkyl halides & $850-550$ & 799.67 \\
\hline $\mathrm{C}=\mathrm{O}($ aldehydes) & $1740-1620$ & 1637.09 \\
\hline $\begin{array}{l}-\mathrm{N}-\mathrm{H}(\text { primary and secondary } \\
\text { amine) }\end{array}$ & $3400-3250$ & 3353.13 \\
\hline $\mathrm{C}=\mathrm{C}$ (aromatic) & $1680-1630$ & 1637.09 \\
\hline $\mathrm{C}-\mathrm{OH}($ alcohols) & $3500-3200$ & 3237.86 \\
\hline
\end{tabular}

Table 10: Gelation and gel meting point temperature of formulations

\begin{tabular}{|c|c|c|c|}
\hline S. No & Formulation Code & Gelation Tem. $\left(\mathbf{T 1}^{\circ}{ }^{\circ} \mathbf{C}\right)$ & $\begin{array}{c}\text { Gel Melting Point Tem. } \\
\mathbf{( T 2}{ }^{\left.\mathbf{C}^{\mathbf{C}}\right)}\end{array}$ \\
\hline 1 & F13 & $35.23 \pm 0.36$ & $68.45 \pm 0.35$ \\
\hline 2 & F14 & $35.26 \pm 0.25$ & $70.23 \pm 0.05$ \\
\hline 3 & F15 & $36.52 \pm 0.55$ & $74.34 \pm 0.45$ \\
\hline 4 & F16 & $35.22 \pm 0.55$ & $72.34 \pm 0.45$ \\
\hline 5 & F17 & $33.22 \pm 0.55$ & $77.34 \pm 0.45$ \\
\hline 6 & F18 & $32.22 \pm 0.55$ & $78.34 \pm 0.45$ \\
\hline
\end{tabular}

Table 11: Viscosity of gel at different rpm of final formulation F15.

\begin{tabular}{|l|l|l|}
\hline S. No & Viscosity of gel & R.P.M \\
\hline 1 & 10 & 14800 \\
\hline 2 & 20 & 9470 \\
\hline 3 & 30 & 7510 \\
\hline 4 & 50 & 5220 \\
\hline 5 & 60 & 4740 \\
\hline 6 & 100 & 3370 \\
\hline
\end{tabular}

Table 12: In-Vitro drug release data of optimized formulation (F) and drug dispersion

\begin{tabular}{|c|c|c|c|}
\hline S.No. & Time (Hrs.) & \%Drug release of Formulation & \% marketed drug \\
\hline 1 & 0 & $0 \pm 0$ & $0 \pm 0.00$ \\
\hline 2 & 0.083333 & $02.5 \pm 0$. & $01.25 \pm$ \\
\hline 3 & 0.166667 & $04.06 \pm 0$. & $02.5 \pm$ \\
\hline
\end{tabular}




\begin{tabular}{|c|c|c|c|}
\hline 4 & 0.25 & $05.62 \pm$ & $03.75 \pm$ \\
\hline 5 & 0.5 & $08.43 \pm$ & $08.43 \pm$ \\
\hline 6 & 1 & $10.93 \pm$ & $16.25 \pm$ \\
\hline 7 & 1.5 & $14.68 \pm$ & $27.81 \pm$ \\
\hline 8 & 2 & $19.37 \pm$ & $40.31 \pm$ \\
\hline 9 & 2.5 & $24.06 \pm$ & $49.06 \pm$ \\
\hline 10 & 3 & $28.75 \pm$ & $65.31 \pm$ \\
\hline 11 & 3.5 & $33.75 \pm$ & $79.06 \pm$ \\
\hline 12 & 4 & $38.43 \pm$ & $91.56 \pm$ \\
\hline 13 & 4.5 & $43.43 \pm$ & \\
\hline 14 & 5 & $48.43 \pm$ & \\
\hline 15 & 5.5 & $53.12 \pm$ & \\
\hline 16 & 6 & $58.43 \pm$ & \\
\hline 17 & 6.5 & $63.43 \pm$ & \\
\hline 18 & 7 & $67.81 \pm$ & \\
\hline 19 & 7.5 & $72.5 \pm$ & \\
\hline 20 & 8 & $75.62 \pm$ & \\
\hline
\end{tabular}

\section{FIGURES}

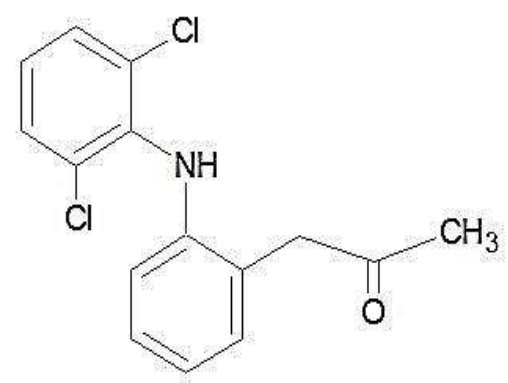

Figure 1: Structure of Diclofenac sodium

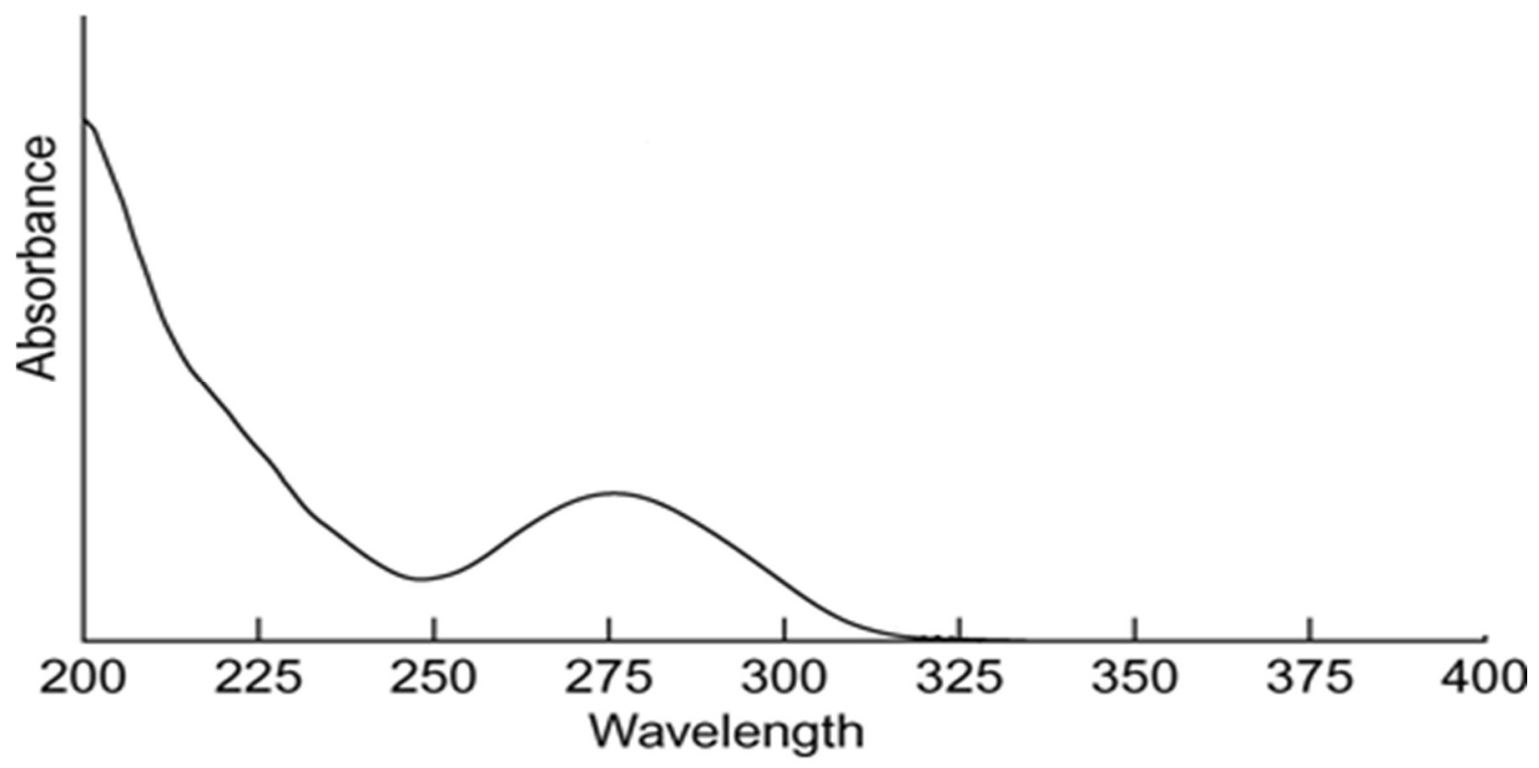

Figure 2: UV Spectrum of the Drug in Water 


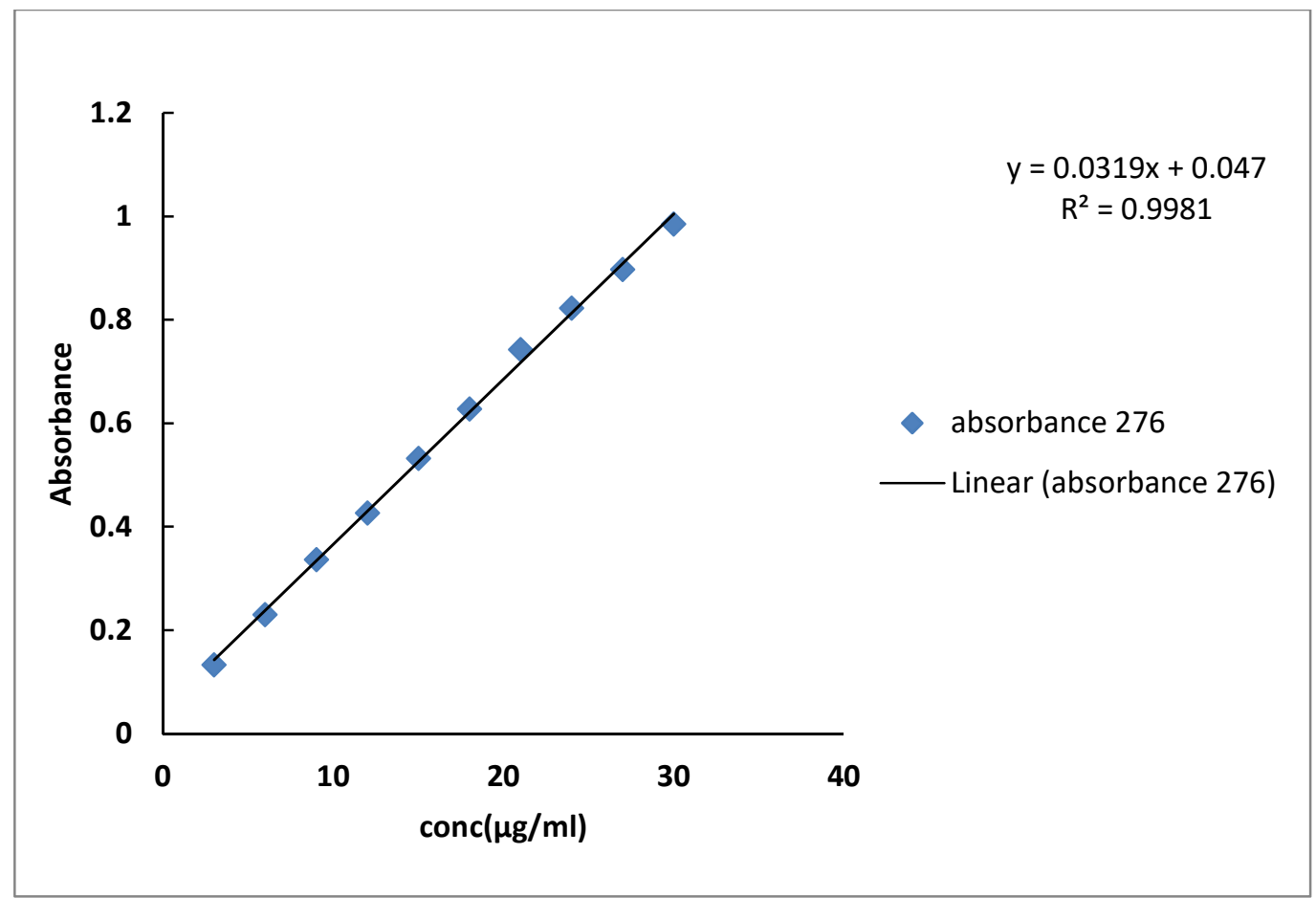

Figure 3: Standard Curve of Diclofenac Sodium in Water

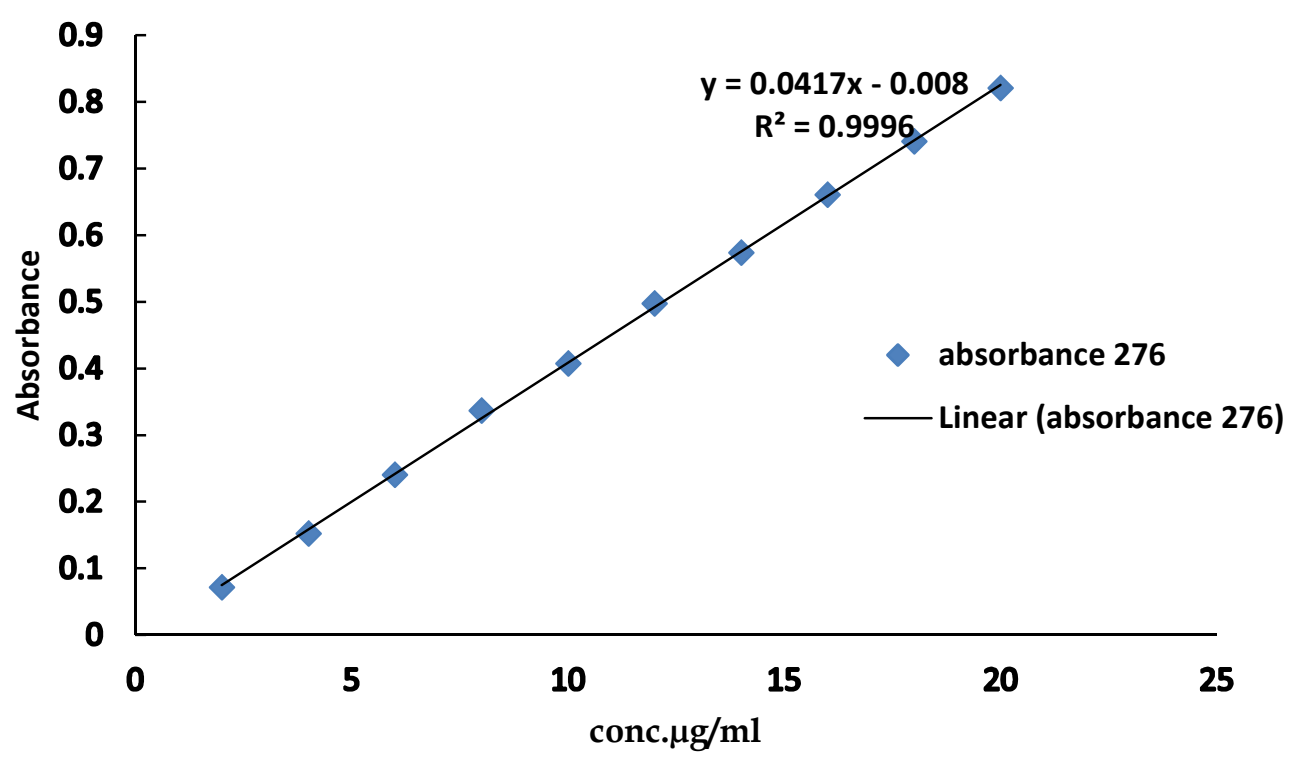

Figure 4: Standard curve of diclofenac sodium in phosphate buffer pH 6.8 


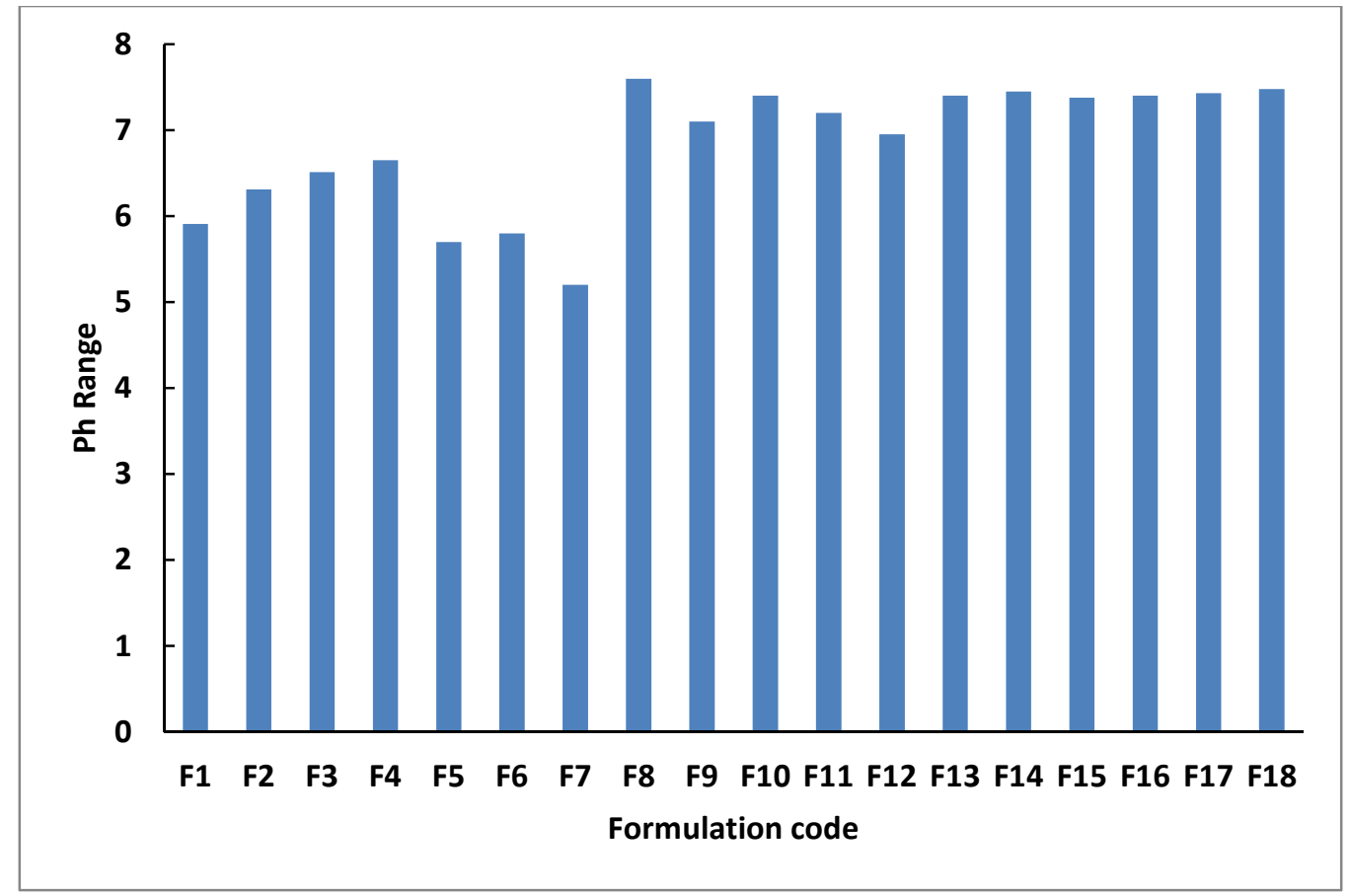

Figure 5: pH and appearance of formulations

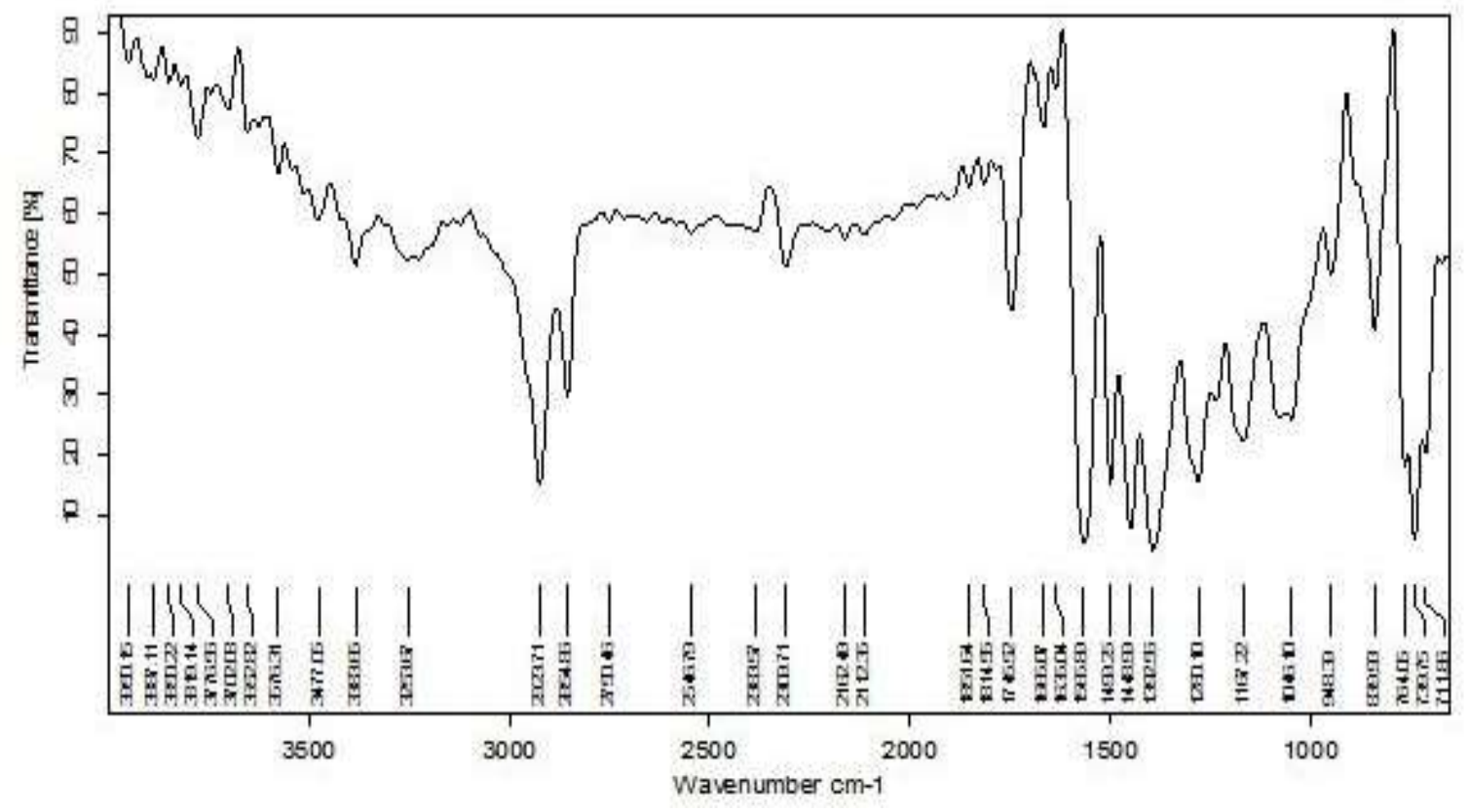

Figure 6: FT-IR spectrum of Diclofenac Sodium 


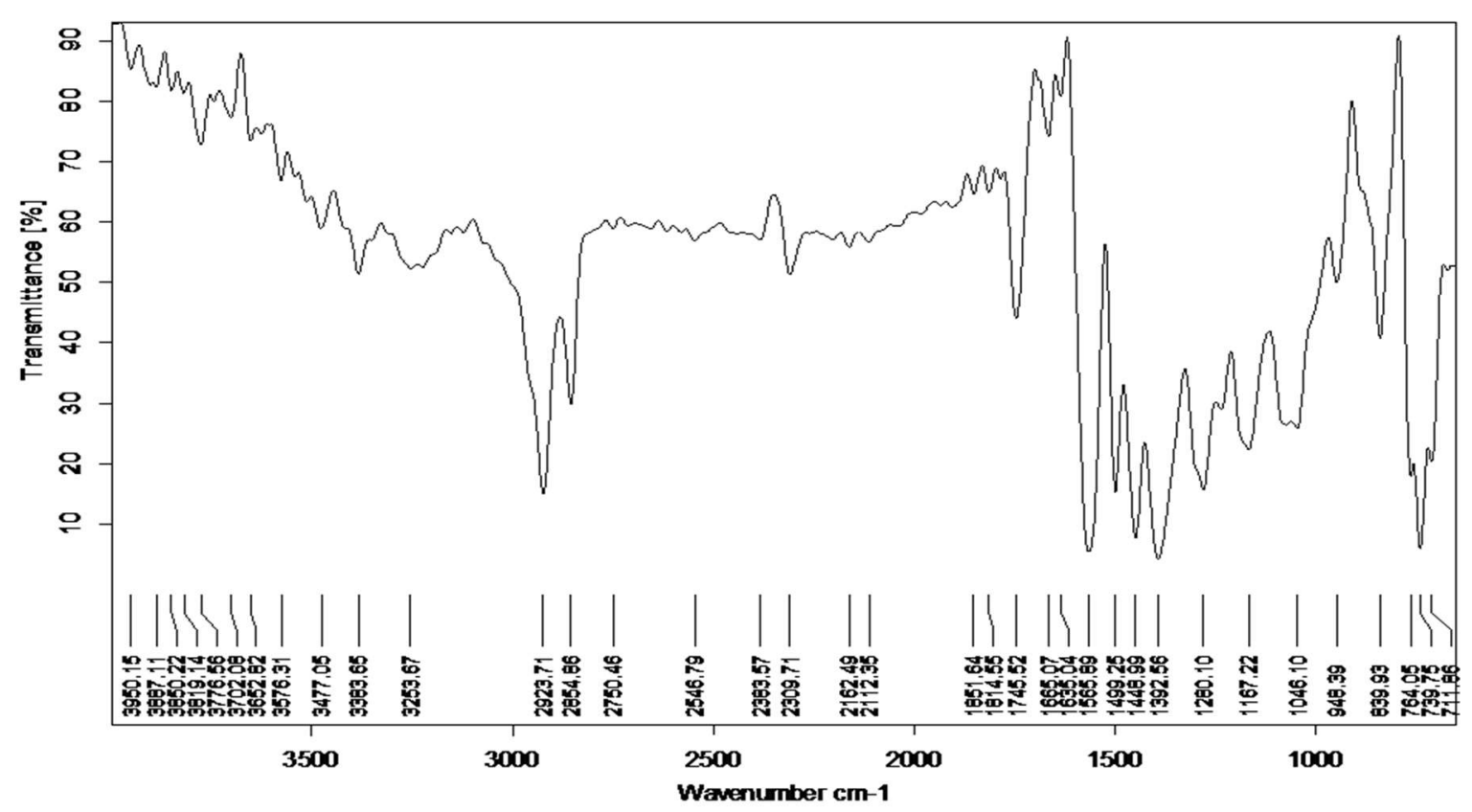

Figure 7: FT-IR spectrum physical mixture

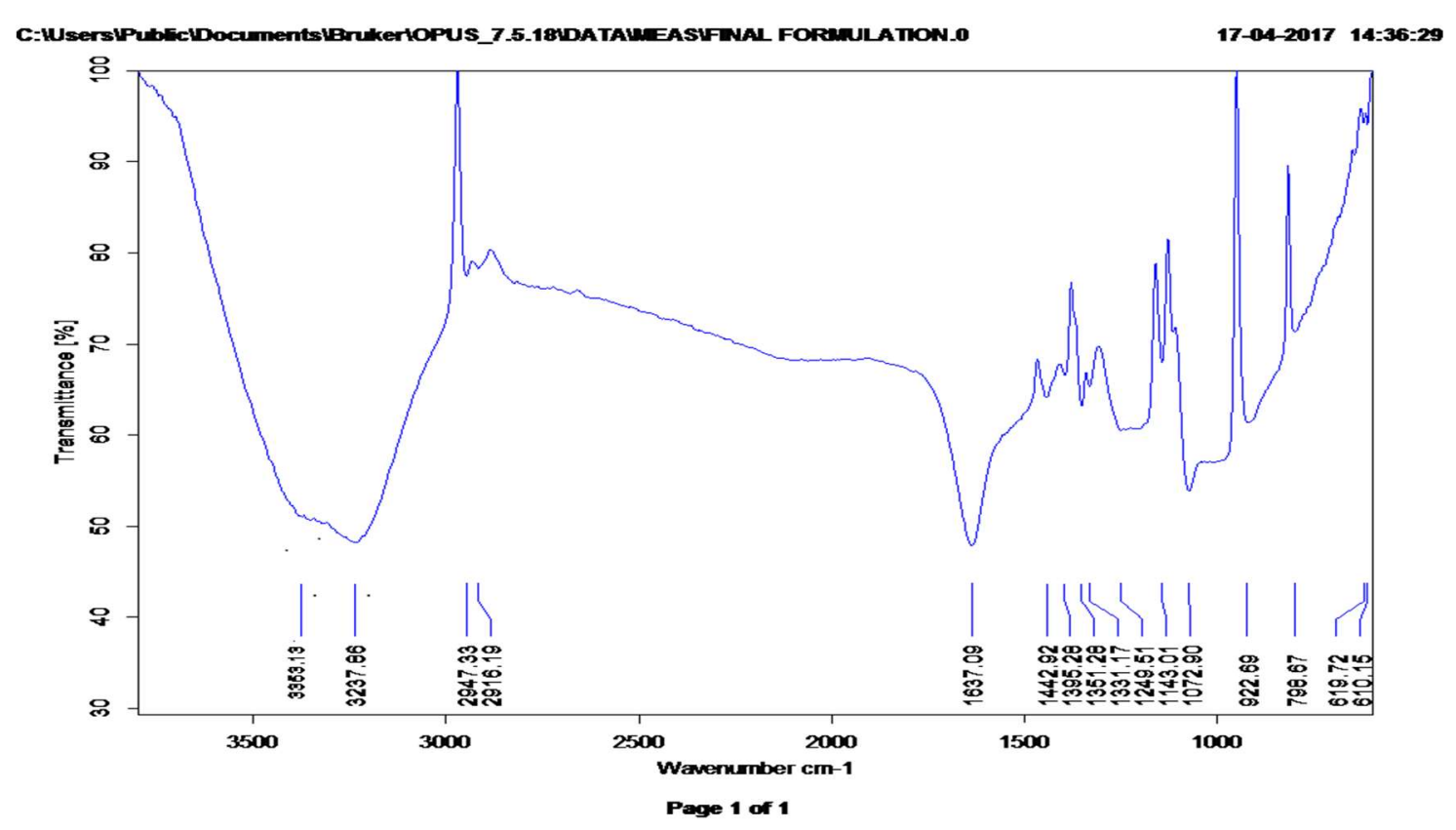

Figure 8: FT-IR spectrum of final formulation 


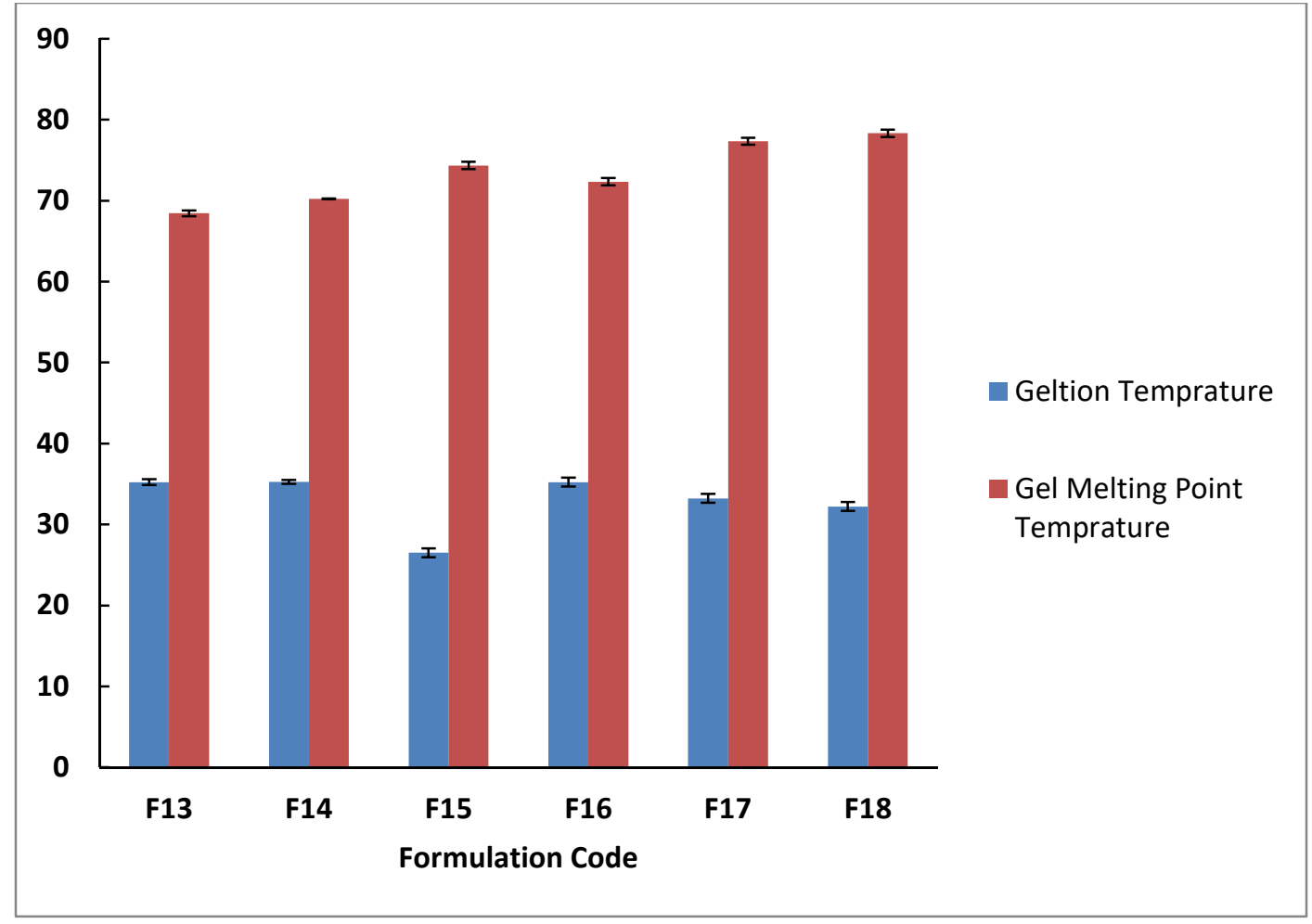

Figure 9: Gelation and gel meting point temperature of formulations

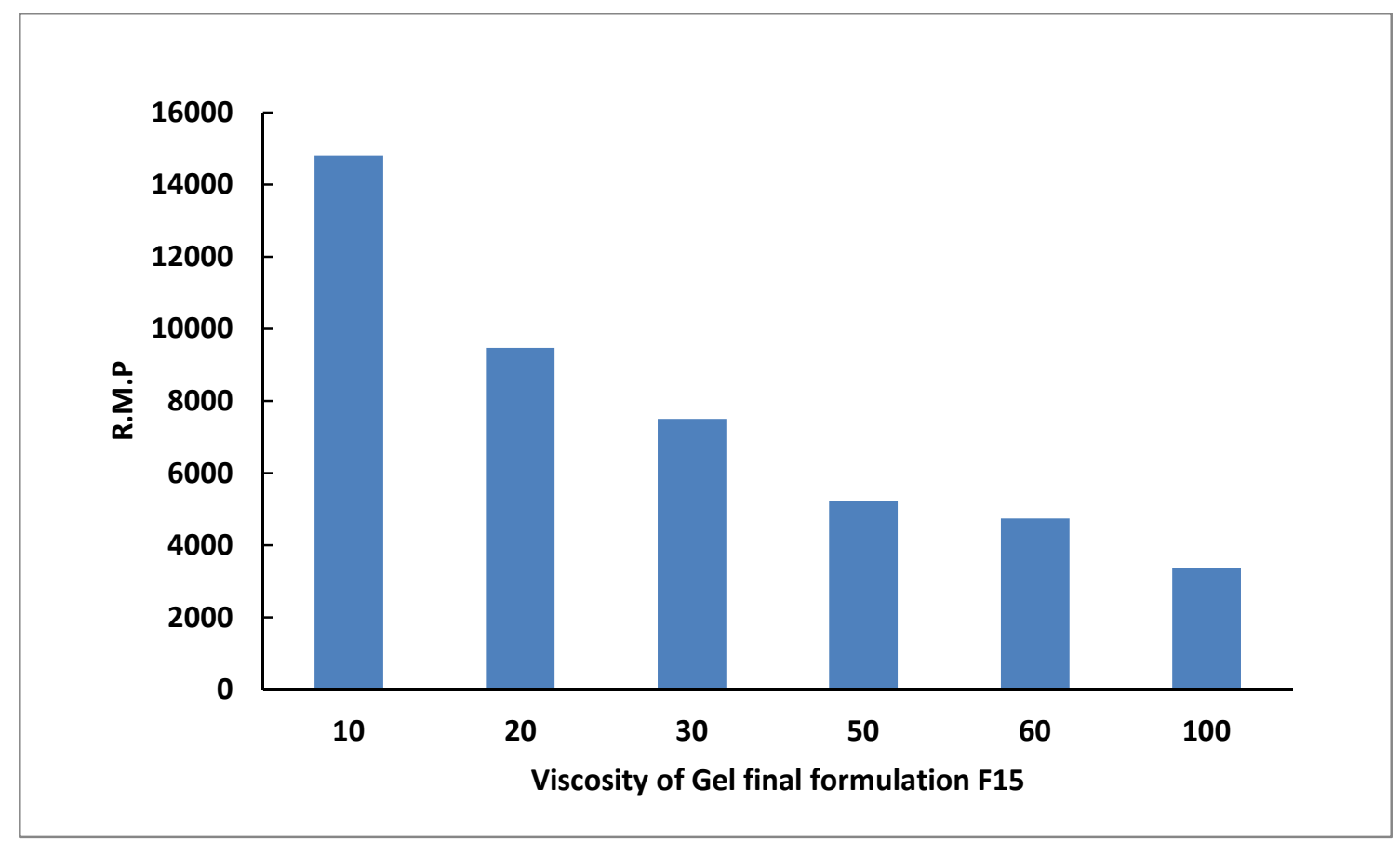

Figure 10: Viscosity of gel final formulation F15 


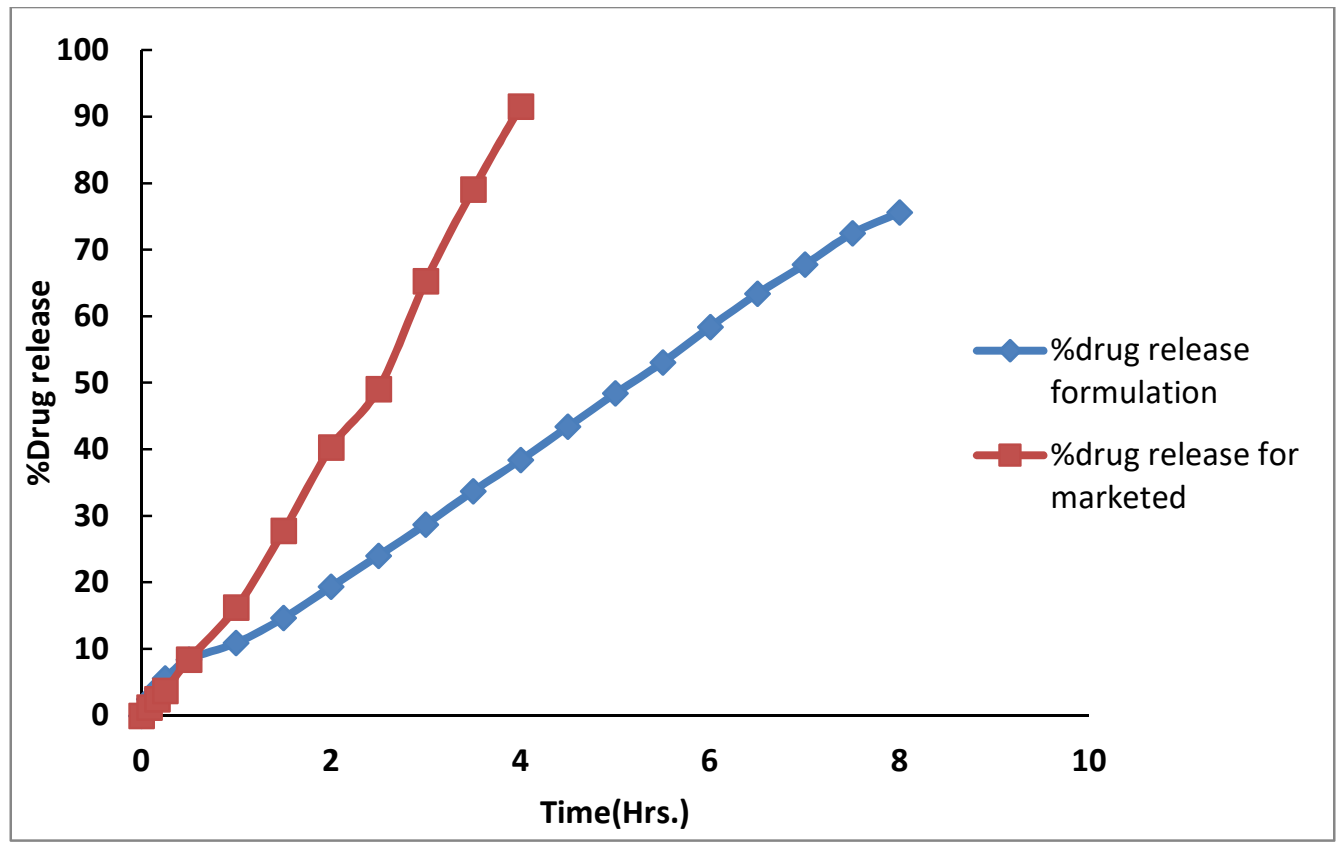

Figure 11: In-Vitro Drug release of Diclofenac sodium loaded ocular gel and pure drug.

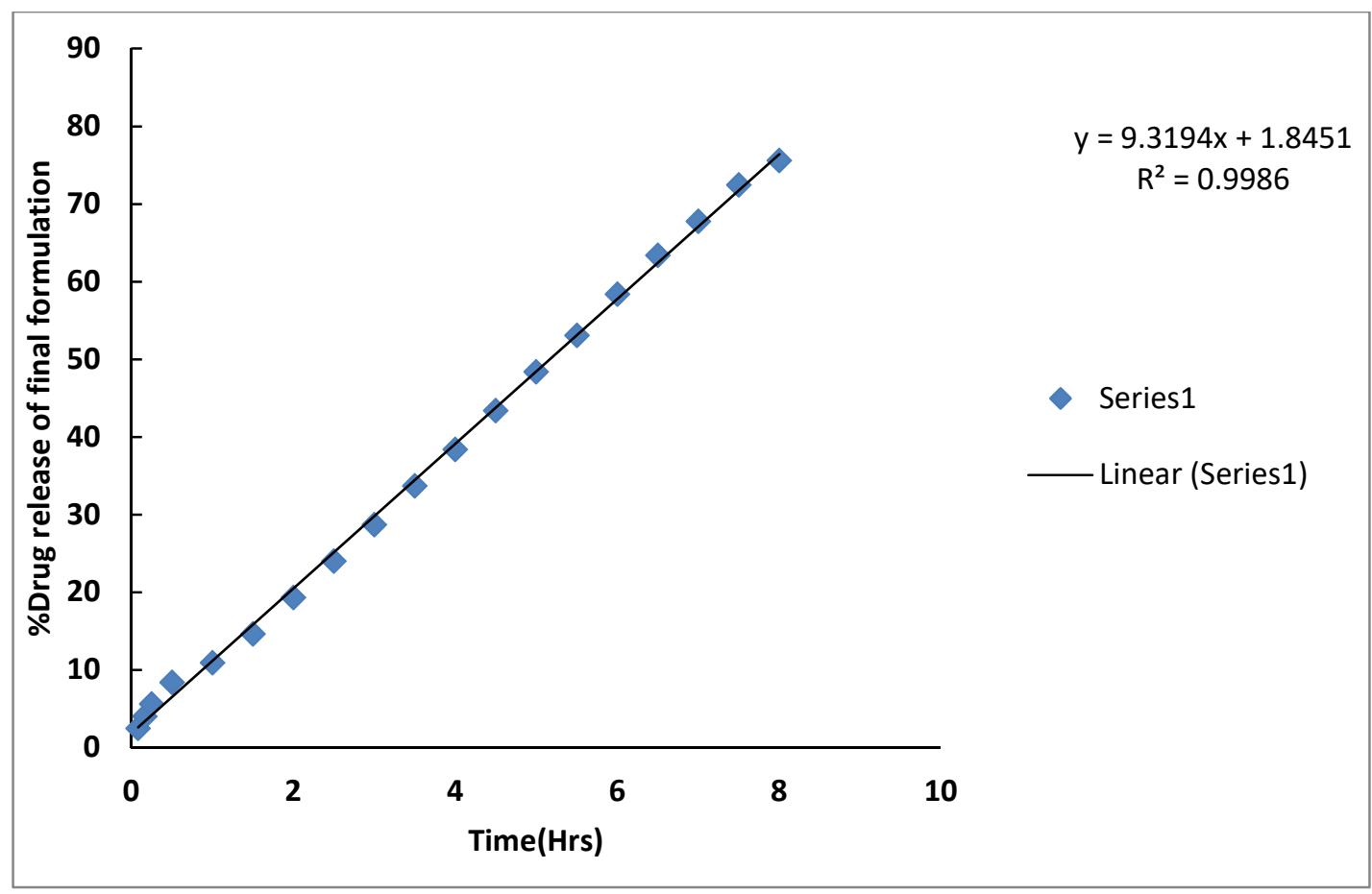

Figure 12: Zero order graph of formulation F12 

PH Sensitive in-Situ Occular Gel of Diclofenac Sodium

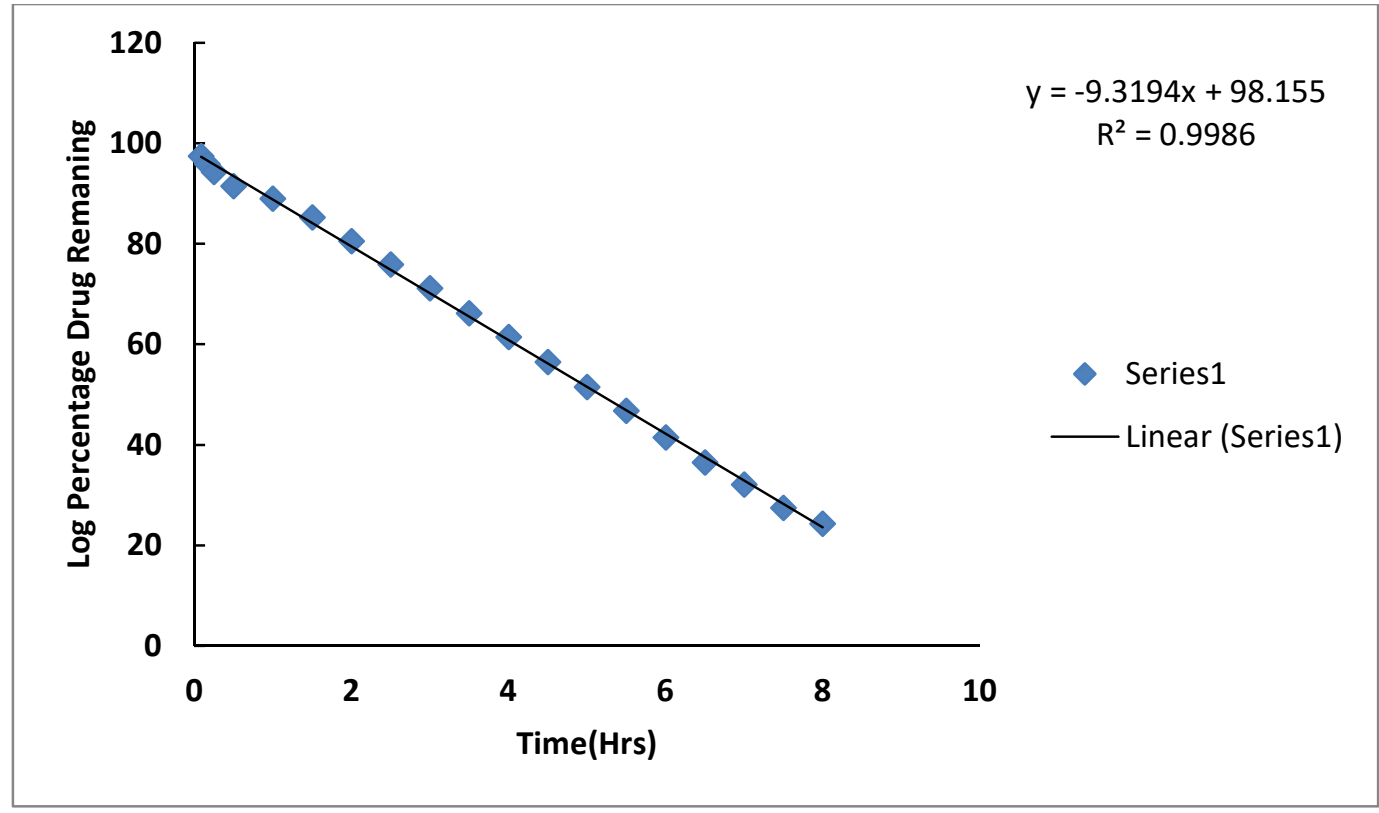

Figure 13: First order graph of formulation F15.

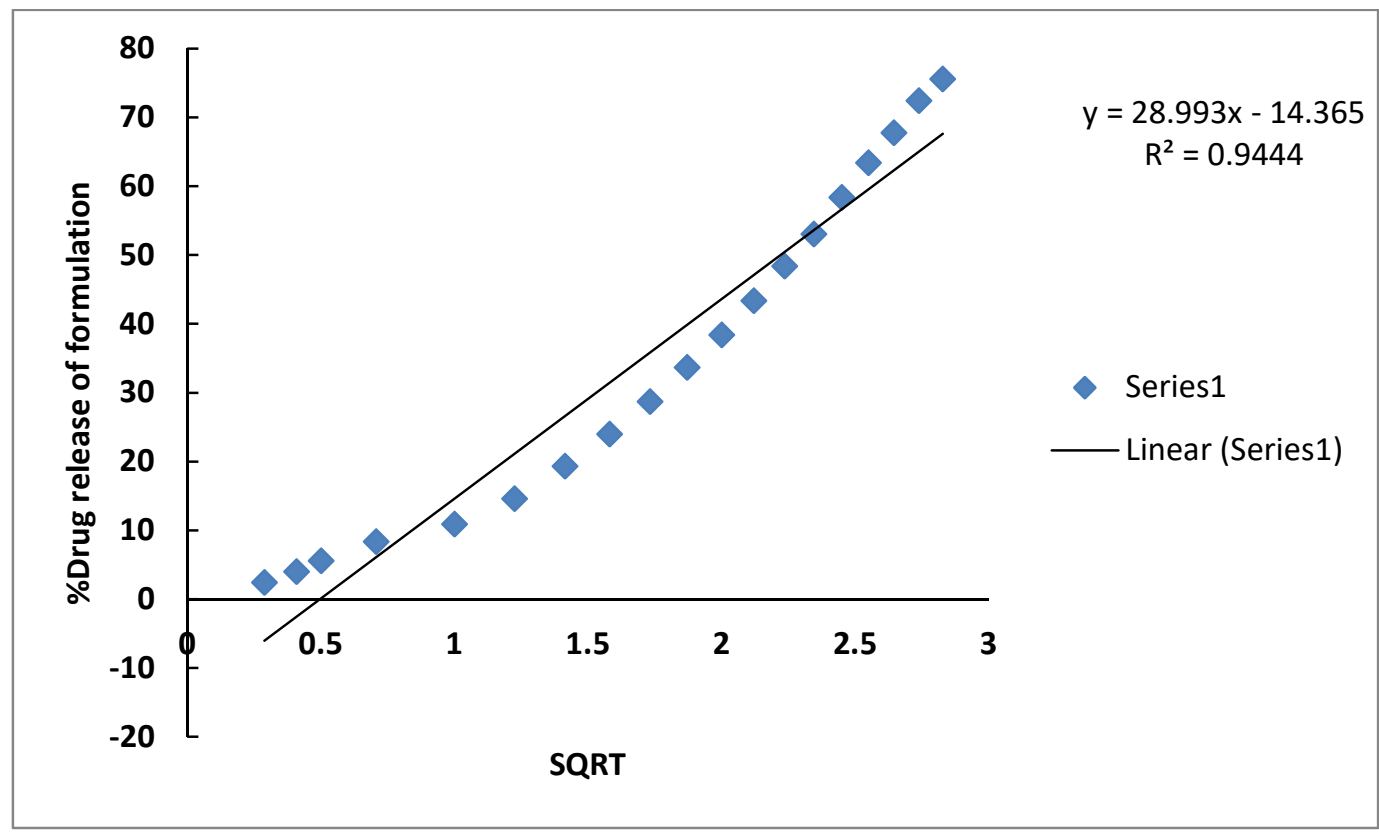

Figure 14: Higuchi order graph of formulation F12 

